\title{
Retrograde reperfusion of renal graft to reduce ischemia- reperfusion injury
}

\author{
Myltykbay Rysmakhanov, Gani Kuttymuratov
}

Department of General Surgery and Transplantation, West Kazakhstan Medical University, Aktobe Medical Center, Aktobe, Kazakhstan

Background: Ischemic reperfusion injury (IRP) of a kidney graft is still a current problem in transplantology. To study the effect of retrograde renal transplant reperfusion on the reduction of IRP during kidney transplantation.

Methods: There are seven kidney transplantations from a living donor were performed using retrograde transplant reperfusion. After the standard laparoscopic donors' nephrectomy, the renal graft was washed with a solution of "NTK" with heparin. After applying an end-to-side venous anastomosis, arterial anastomosis was applied. At the same time, retrograde reperfusion of the graft with venous blood was performed, then a typical antegrade reperfusion followed. Immunosuppression was a three-component: $\mathrm{CNI}+\mathrm{MMF}+$ steroid with Basiliximab induction. Blood perfusate from the artery was analyzed for blood gas analysis; creatinine and urea were analyzed on the 1st, 3rd, 7th, 14th, and 30th days after surgery.

Results: In all cases, the graft function was satisfactory. There were no vascular complications, there were no reanastomosis during the operation. Significant changes in $\mathrm{pH}, \mathrm{PO}_{2}, \mathrm{BEecf} \mathrm{HCO}_{3}{ }^{-}, \mathrm{Lac}, \mathrm{K}+$, and $\mathrm{Ca}^{2+}$ values were observed in retrograde blood. Normalization of serum creatinine and urea levels was observed on average on the 4 th day after surgery. There were no indications for diagnostic biopsy of a kidney graft.

Conclusions: The results of the initial experience of kidney transplantation using retrograde reperfusion show an improvement in the function of the kidney transplant. In the future, an increase in the cohort of patients is required to study the effect of retrograde reperfusion.

Corresponding author: Myltykbay Rysmakhanov

E-mail: mrtransplantolog@gmail.com

(c) The Korean Society for Transplantation

This is an Open Access article distributed under the terms of the Creative Commons Attribution Non-Commercial License (http://creativecommons.org/licenses/by-nc/4.0/) which permits unrestricted non-commercial use, distribution, and reproduction in any medium, provided the original work is properly cited. 